\title{
Co morbidity and Neuroimaging in Alzheimer's Disease
}

\begin{abstract}
Tsolaki Anthoula ${ }^{1 *}$, Siapera Marianna ${ }^{2}$, Mauredaki Penelope ${ }^{2}$, Kantoglou Eleni' ${ }^{2}$, Patrizia Mecocci ${ }^{3}$, Bruno Vellas ${ }^{4}$, Hilkka Soininen ${ }^{5}$, Iwona Kloszewska ${ }^{6}$, Anna Kisney ${ }^{7}$, Andy Simmons ${ }^{7}$, Simon Lovestone ${ }^{8}$, Tsolaki Magda², On behalf of the Addneuromed consortium
\end{abstract}

${ }^{1}$ Neurology Clinic, Agios Pavlos Hospital, Greece

${ }^{2} 3$ rd Department of Neurology, Aristotle University of Thessaloniki, Greece

${ }^{3}$ Department of Gerontology and Geriatrics, University of Perugia, Italy

${ }^{4}$ Department of Neurology, University of Toulouse, France

${ }^{5}$ Department of Neurology, University of Kuopio, Finland

${ }^{6}$ Department of Old Age, Psychiatry and Psychotic Disorders, Medical University of Lodz, Poland ${ }^{7}$ MRC Centre for Neurodegeneration Research, Institute of Psychiatry King's College London, UK

${ }^{8}$ Department of Psychiatry, University of Oxford, UK

*Corresponding author: Tsolaki Anthoula, Neurology Clinic, General Hospital of Thessaloniki, Ellis Alexiou 19, 55535 Thessaloniki, Greece



\begin{abstract}
Multiple medical co morbid conditions are common in older adults. Patients with dementia and high comorbidity are characterized by the most compromised health status. This study aims to assess the correlation of Magnetic Resonance Imaging (MRI) data and medical co morbidity in patients with Alzheimer's disease (AD). The study is based on data collected from the European Study Innomed. Clinical and MRI data were collected from six European sites. Patients had to meet the ADRDA/NINCDS and DSM -IV criteria, and the MMSE score was $\leq 23$. A total of 61 AD patients' data, were analyzed. The Cumulative Illness Rating Scale for Geriatrics (CIRS-G) was used to calculate the co morbidity burden. MRI volume of 14-brain regions of interest, mostly mentioned as affected by AD in literature, were analyzed. The impact of co morbidity, on the volume of the selected MRI areas of the 61 patients with AD, was assessed via Spearman correlation coefficient. The correlation of CIRS-G with the volume of the brain areas of interest showed that there was no statistically significant correlation. Co morbidities, based on our results, do not largely influence the brain volume of the investigated areas, additionally to the neurodegenerative disease. Age and gender are confounders regarding the brain atrophy in AD.
\end{abstract}

\section{Introduction}

Alzheimer's Disease (AD) is among the most common diseases in aging societies, and its prevalence is expected to quadruple in 2050 [1]. The incidence of AD increases steeply with age and continues to increase even in the most advanced ages. Neuropathologically, it is characterized by the aggregation and deposition of misfolded proteins such as $\beta$-amyloid mainly as extracellular neuritic plaques and hyperphosphorylated tau protein as intracellular neurofibrillary tangles [2]. Several studies presented that the incidence of $\mathrm{AD}$ in the United States and Europe is higher in females than in males, especially at very old ages $[3,4]$. Moreover, it seems to exist an excess mortality in men with AD [5]. However, the survival advantage of women with $\mathrm{AD}$ relative to men may occur as a result of fewer co morbid clinical conditions associated with the diagnosis of dementia [6]. But are these two conditions (AD and medical co morbidity) somehow connected one to the other?
Co morbidities are diseases or disorders that coexist with a disease of interest. Co morbid illnesses are important because they may delay diagnosis, may influence treatment decisions, they are related to complications, and last but not least may alter survival [7]. Multiple medical co morbid conditions are common in older adults with and without dementia in primary care [8]. Patients with Dementia (PwD) are more frequently frailer than older people. They have a higher number of admissions to hospital [9], a greater prevalence of complications and an increased risk of death $[10,11]$.

When compared to older adults with no dementia, PwD and high comorbidity reported the most compromised health status, especially in those with sight, oral, and genito-urinary problems [12]. Co morbid medical conditions, such as diabetes [13-15], hypertension $[16,17]$ and other cardiovascular risk factors $[18,19]$ 
may also contribute to the progression of $\mathrm{AD}$ patients [20,21], and can even contribute in the onset of walking and eating disability in PwD [22]. On the other hand, dementia reduces the self-care status, so the ability to control other chronic conditions becomes difficult and complicated [14].

AD is characterized mainly by brain atrophy in hippocampus and in some cortical areas at the onset of the disease. Chronic medical conditions may also cause brain atrophy, i.e. chronic cigarette [23] and alcohol use -abuse [24], hypertension [25,26], kidney disease [27], depression [28].

This study aimed to examine the effect of co morbidity, regarding the number and the severity of comorbid entities, on the volume of 15 different brain areas most affected by $\mathrm{AD}$.

\section{Material and Methods}

\section{Participants}

The study was based on a database which was collected from the European study Innomed, an FP project funded by the EU and sponsored by EFPIA [29]. Clinical, neurocognitive and MRI data, were collected from six different European sites: Aristotle University of Thessaloniki, University of Perugia, University of Kuopio, Medical University of Lodz, University of Toulouse and Institute of Psychiatry King's College. Two hundred twenty AD patients were recruited from the six sites-countries. All participants signed a consent sheet according to the Helsinki agreement. The AD patients met the NINCDS-ADRDA (National Institute of Neurological and Communicative Disorders and Alzheimer's Disease and Related Disorders) [30] and DSM-IV criteria [31] for the probable AD. Inclusion criteria were age more than 58 years old, and MiniMental State Examination score $\leq 23$. The exclusion criteria were significant neurological or psychiatric illness other than $\mathrm{AD}$ and significant systematic illness or organ failure.

\section{Co morbidity assessment}

Co morbidity refers to any other coexistent illness additional to the disease of interest, in this case, AD. In this study, the available information on co morbidity in $\mathrm{AD}$ patients was from Cambridge Mental Disorders of the Elderly Examination (CAMDEX) test which includes patient's past and current medication.

Table 1: The modified Cumulative Illness Rating Scale (CIRS)

\begin{tabular}{|c|c|c|c|c|c|c|}
\hline \multirow{2}{*}{$\begin{array}{c}\text { Body System } \\
\text { 1. Cardiac (heart only) }\end{array}$} & \multicolumn{6}{|c|}{ Score } \\
\hline & 0 & 1 & 2 & 3 & 4 & 5 \\
\hline 2. Hypertension (rating is based on severity; organ damage is rated separately) & 0 & 1 & 2 & 3 & 4 & 5 \\
\hline 3. Vascular (blood, blood vessels, and cells, bone marrow, spleen, lymphatics) & 0 & 1 & 2 & 3 & 4 & 5 \\
\hline 4. Respiratory (lungs, bronchi, trachea below the larynx) & 0 & 1 & 2 & 3 & 4 & 5 \\
\hline 5. EENT (eye, ear, nose, throat, larynx) & 0 & 1 & 2 & 3 & 4 & 5 \\
\hline 6. Upper GI (esophagus, stomach, and duodenum; pancreas; do not include diabetes) & 0 & 1 & 2 & 3 & 4 & 5 \\
\hline 7. Lower GI (intestines, hernias) & 0 & 1 & 2 & 3 & 4 & 5 \\
\hline 8. Hepatic (liver and biliary tree) & 0 & 1 & 2 & 3 & 4 & 5 \\
\hline 9. Renal (kidneys only) & 0 & 1 & 2 & 3 & 4 & 5 \\
\hline 10. Other GU (ureters, bladder, urethra, prostate, genitals) & 0 & 1 & 2 & 3 & 4 & 5 \\
\hline 11. Muscolo-skeletal-integumentary (muscle, bone, skin) & 0 & 1 & 2 & 3 & 4 & 5 \\
\hline 12. Neurological (brain, spinal cord, nerves, do not include dementia) & 0 & 1 & 2 & 3 & 4 & 5 \\
\hline 13. Endocrine-Metabolic (includes diabetes, thyroid; breast; systemic infections; toxicity) & 0 & 1 & 2 & 3 & 4 & 5 \\
\hline
\end{tabular}

The Modified Cumulative Illness Rating Scale for Geriatrics (CIRS-G) was used in this study. CIRS scale has been predominantly reported in the geriatric and psychiatric literature. It was formulated in 1992 as a revision of the Cumulative Illness Rating Scale (CIRS) [32] to reflect common problems of the elderly [33]. In this study, we used the modified CIRS-G version [34]. Diseases are scored by organ system and grouped into 14 categories (Table 1). Each item is given a severity score: 0 . No problem;

A. Current mild problem or past significant problem;

B. Moderate disability or morbidity/requires first-line therapy;

C. Severe/constant significant disability/ uncontrollable chronic problems;
D. Extremely severe/immediate treatment required/ end organ failure/severe impairment in function. Five main composite scores can be calculated: the total number of categories endorsed; CIRS-G total score; severity index (Total score/total number of categories endorsed); the number of categories at level 3 severity; the number of categories at level 4 severity.

For the present study, the score for the psychiatric illness item was calculated without dementia-related ratings. We also scored for the respiratory item, smoking as 0 : no/less than 10/day; 1: 1020 cigarettes /day for more than one years, 2: 20+cigarets/day for more than one years, since this was the form of information that has been noted down in the CAMDEX. Furthermore, when we had daily use of anti-depressive drugs, we scored it as 2 because it is very common in elderly to have mood disorders without having 
major depression according to DSM IV criteria and we believe that it would be overscored as 3 .

If the subject had two illnesses in the same body system, it was rated by the score of the most severe one and not the sum of both of them, according to the instructions of modified CIRS application [33]. The severity of dementia was calculated by MMSE and CDR and the impact of its severity on brain volumes was checked by the statistical analysis.

\section{MRI}

Participants: One hundred nineteen patients with probable AD underwent MRI. Informed consent was obtained from all subjects and protocols and procedures were approved by the relevant Institutional Review Board at each data acquisition site and the data coordination site.

Data acquisition: Data acquisition took place using six different 1.5T MR systems (4 General Electric, 1 Siemens and 1 Picker) at the University of Kuopio, Finland, the University of Perugia, Italy, Aristotle University of Thessaloniki, Greece, King's College London, United Kingdom, the University of Lodz, Poland and the University of Toulouse, France. At each site, a quadrature birdcage coil was used for $\mathrm{RF}$ transmission and reception. Data acquisition was designed to be compatible with the Alzheimer Disease Neuroimaging Initiative (ADNI) [35]. Following a three-plane localizer, a high resolution sagittal 3D MP-RAGE dataset and an axial proton density / T2-weighted dual echo fast spin echo dataset was acquired. Image quality control took place immediately after the images had been acquired at each site according to clear criteria. All MR images received a clinical read by an on-site radiologist to exclude any subjects with non-AD related pathologies.

Image analysis: Following detailed quality control of each set of images two highly automated structural MRI data analysis pipelines were utilized for data analysis and hippocampal volumes delineated manually.

Civet pipeline: The civet pipeline consists of image intensity non-uniformity correction using the N3 algorithm [36], segmentation of brain tissue using an artificial neural network classifier [37], and regional brain parcellation using a multi-scale analysis method which deforms the T1-weighted MPRAGE volume to match a previously labeled MRI [38].

Fischl and dale pipeline: The Fischl and Dale pipeline includes the removal of non-brain tissue, segmentation of the subcortical white matter and deep gray matter volumetric structures [39,40] intensity normalization [36] and parcellation of the cerebral cortex into units based on gyral and sulcal structure [40,41].
Hippocampal volumes: Hippocampal volumes were manually delineated by an experienced neuroradiologist according to the method described in bibliography [42]. The detailed description of the procedure has been already published in previous papers of the same scientific group (Addneuromed) [43]. Brain changes in $\mathrm{AD}$ and prodromal $\mathrm{AD}$ lead to a pattern of widespread atrophy (measured as both volume and thickness), involving several different structures across the brain (e.g., hippocampus, entorhinal cortex, and frontal cortices).

For this study, 14 variables, 12 regional volumes obtained from the pipeline were used to check the impact of co morbidity in addition to the already existing neurodegenerative disease.: Normalized brain volume, Hippocampus volume left hemisphere as determined by Yi (manual segmentation), Hippocampus volume right hemisphere as determined by Yi (manual segmentation), Total hippocampus volume as determined by Yi (manual segmentation), Entorhinal cortex, Left cerebral cortex, Left cerebral white matter, Left hippocampus, Right cerebral cortex, Right cerebral white matter, Right hippocampus, Para-hippocampal gyrus, Left amygdale, Right amygdale (hippocampal volume was analyzed for both manual segmentation and computerized). All volumetric measures from each subject were normalized relative to the subject's intracranial volume. The chosen structures are multiply mentioned as AD-affected areas.

\section{Statistical Analysis}

Data analysis was conducted with SPSS 20.0 (SPSS Inc., Chicago, IL) statistical software. The Kolmogorov-Smirnov test was used to assess normality of the continuous variables. The Spearman's rank coefficient was calculated for the assessment of the linear relationship between the co morbidity index and the volume of each of the 14-brain area variable. Significant correlations were further explored via linear regression analysis to adjust for age, education, MMSE and CDR scores. P-values less than 0.05 were considered statistically significant.

\section{Result}

A total of 220 Alzheimer's disease patients were examined at baseline. The sample consisted of 73 men $(33,2 \%)$ and 147 women $(66,8 \%)$. MMSE test was 20, 04 $\pm 5,03$ (mean \pm Std. Deviation). From those, 119 had an MRI, 98 patients had full medical history to assess CIRS and only 61 MMSE score $\leq 23$. Therefore 61 patients' data were more analyzed; 19 males (31,1\%) and 42 females $(68.9 \%)$. The average MMSE was $17.93(\mathrm{SD}=3.605)$, the average age 75.67 $(S D=6,81)$ years old, and the average of education (in years) 7.18 $(\mathrm{SD}=3.79)$ (Table 2).

Table 2: Demographic data.

\begin{tabular}{|c|c|c|c|c|c|}
\hline \multicolumn{7}{|c|}{ Descriptive Statistics } \\
\hline & N & Minimum & Maximum & Mean & Std. Deviation \\
\hline Age in years at MRI visit & 61 & 58,229 & 87,762 & 75,664 & 6,811 \\
\hline
\end{tabular}




\begin{tabular}{|c|c|c|c|c|c|}
\hline Education & 61 & 0 & 17 & 7,18 & 3,788 \\
\hline MMSE score & 61 & 12 & 23 & 17,93 & 3,605 \\
\hline
\end{tabular}

Table 3: Table of spearman's rank coefficients followed by respective significance.

\begin{tabular}{|c|c|c|}
\hline \multirow{2}{*}{ Brain Structures Volume $(\mathrm{N}=61)$} & \multicolumn{2}{|c|}{ Comorbidity Severity Index } \\
\hline & Spearman's Rho & $\mathbf{P}$ \\
\hline Normalized brain volume & 0.229 & 0.076 \\
\hline Hippocampus volume left hemisphere as determined by Yi (manual segmentation) & 0.061 & 0.638 \\
\hline Hippocampus volume right hemisphere as determined by Yi (manual segmentation) & 0.09 & 0.49 \\
\hline Total hippocampus volume as determined by Yi (manual segmentation) & 0.074 & 0.572 \\
\hline Entorhinal cortex $(\mathrm{N}=59)$ & 0.243 & 0.064 \\
\hline Left cerebral cortex & 0.116 & 0.373 \\
\hline Left cerebral white matter & 0.011 & 0.931 \\
\hline Left hippocampus & 0.101 & 0.437 \\
\hline Right cerebral cortex & 0.21 & 0.104 \\
\hline Right cerebral white matter & 0.029 & 0.824 \\
\hline Right hippocampus & 0.159 & 0.221 \\
\hline Parahippocampal gyrus $(\mathrm{N}=59)$ & 0.108 & 0.407 \\
\hline Left amygdala & -0.051 & 0.698 \\
\hline Right amygdala & 0.183 & 0.158 \\
\hline
\end{tabular}

P-values $<0.05$ were considered statistically significant.

Correlation analysis showed no statistically significant correlation between the co morbidity Index's value and the brain areas under investigation. Adjusting for covariates such as age, gender, educational level, MMSE score and CDR score did not alter these results. A low negative correlation that was found between the cerebral cortex and CIRS was not deemed significant (Table 3).

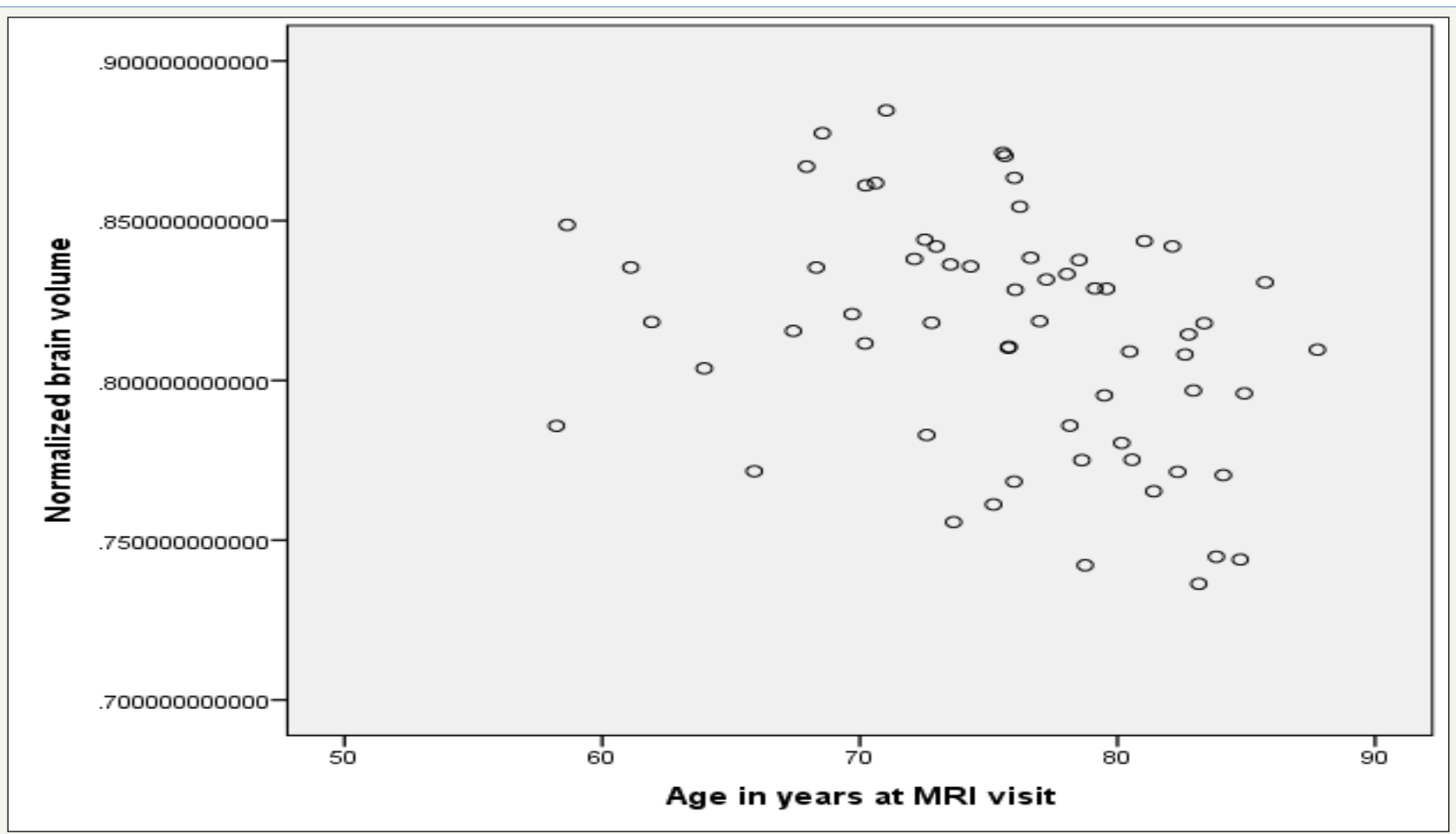

Figure 1: Age effect on normalized total brain volume. 
a.

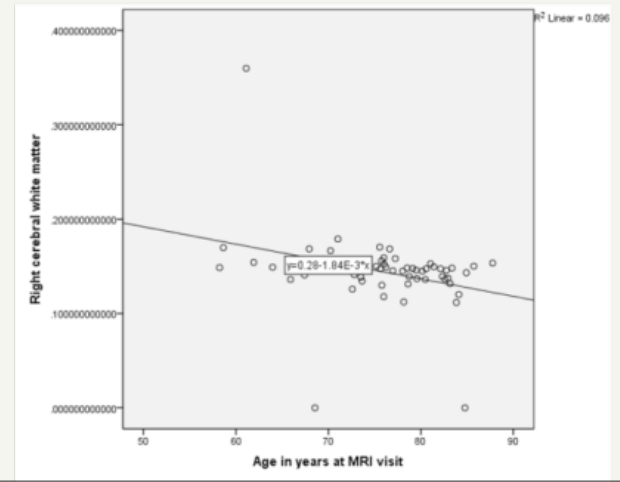

b.

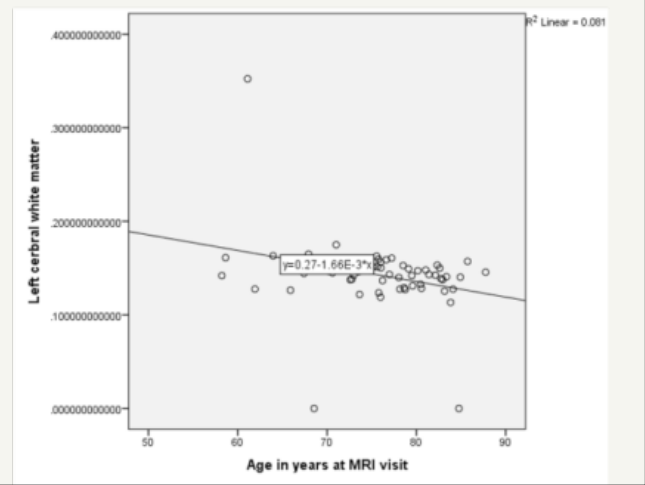

Figure 2: White matter volumes decrease due aging.

a. Right hemisphere and

b. Left hemisphere.

Stepwise linear regression analysis model building was used to adjust for age, gender, education, MMSE and CDR scores. Age is correlated with Normalized brain volume $(p=0.004)$ (Figure 1$)$, as well as left $(p=0.020)$ and right $(p=0.011)$ cerebral white matter (Figure 2). As age increases the normalized total volume reduces $(B=-0.002$ 95\% CI: $-0.003-0.001, p=0,004)$. The age increase is also related to white matter shrinkage bilaterally $(B=-0.002,95 \%$ CI: $-0.003-0.0002, p=0.020$ and $B=-0.002,95 \%$ CI: $-0.003-0.0004$, $\mathrm{p}=0.011)$. Gender is correlated with Hippocampus volume right $(p=0.012)$ and left $(p=0.031)$ hemisphere as determined by Yi, manually (Figure 3$)$, as well as right $(p=0.006)$ hippocampus volume by computerized segmentation. The hippocampus volume of the right hemisphere as determined by Yi is $2.40 \times 10-7$ smaller in male than in female (B=-2.40x10-7, 95\% CI: $-4.29 \times 10-7-5.29 \times 10-$ $7, p=0.012$ ). The hippocampus volume of the left hemisphere as determined by $\mathrm{Yi}$ is $1.80 \times 10-7$, also smaller in male than in female $(\mathrm{B}=-1.80 \times 10-7,95 \% \mathrm{CI}:-3.44 \times 10-7-1.67 \times 10-8, \mathrm{p}=0.031)$. a.

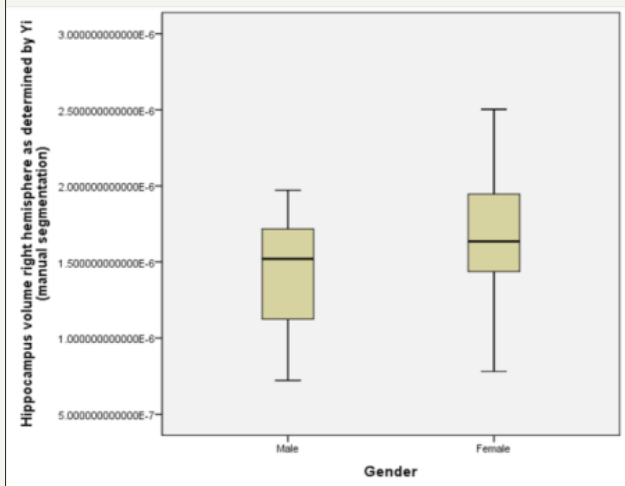

b.

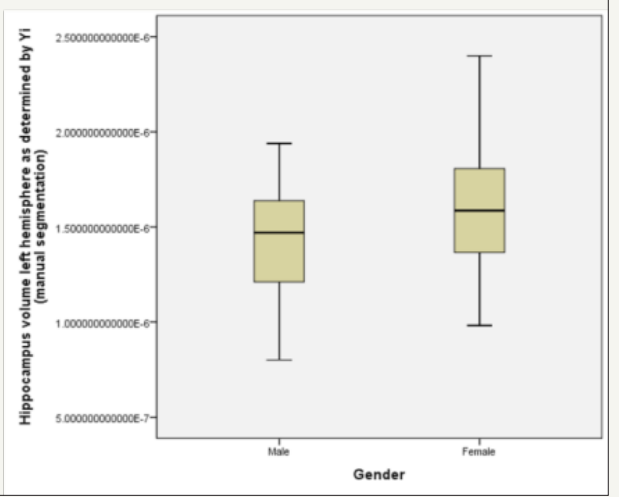

Figure 3: Differences between gender regarding hippocampal volume as determined by Yi.

a. Right hemisphere and

b. Left hemisphere.

The right hippocampus volume by computerized segmentation is 0.00041 smaller in male than in female $(B=-0.00041,95 \% \mathrm{CI}$ : $-0.001-0.00012, \mathrm{p}=0.006)$.

\section{Discussion}

Co-existence of other pathological situations in patients who suffer from dementia is very important [20,44-46]. The magnitude of co morbidity in patients with dementia is similar to that in those without [20]. Very old patients, with dementia or not, have similar levels of co morbidity, but patients with dementia had a poorer functional and nutritional status [47]. Medical co morbidity is strongly associated with functional status and cognition in PwD [48] and make them more frail and more susceptible to pharmacological AEs than the older population without dementia [10]. Therefore, it should be taken into account in the management of patients with dementia [49]. 
Multiple morbid conditions have also been considered as risk factors for dementia, especially cardiovascular diseases, and may cause brain atrophy as well. Hypertension is a well- known risk factor for dementia [50-54] and is quite common in patients with AD. It is present in $44.1 \%$ of patients with mild to moderate $\mathrm{AD}$ according to the literature [55], but this percentage may vary depending on the age of the studied population [20]. Hypertension also correlates with cognitive decline before the diagnosis of dementia [56-58].

The most common explanation for the deleterious effect of hypertension on cognition is that hypertension increases the risk of cerebrovascular disease. Hypertension can lead to lacunar infarcts and white matter disease and eventually to neuronal loss [59-61]. Hypertension has also been associated with structural brain changes as well, even before the onset of dementia. There is a claim in the literature that hypertension is responsible for central brain atrophy [62] and hippocampus [63]. However, a recent study by Meurs et al. although presented brain volume loss in certain regions of interest (ROIS), showed no volume loss in the hippocampus, which consists a ROI for our study [64]. So, the relationship between hypertension and brain volume loss remains a rather ambiguous subject.

Diabetes mellitus (DM), is regarded as an AD risk factor, seems to be responsible for atrophic changes particularly in the anterior frontal lobe. These changes can occur as early as the first year after the clinical diagnosis of type 2 DM [65]. It is also known that when the DM is present with heart failure, has also been correlated to structural brain change $[66,67]$, i.e., there are smaller total and cortical lobar brain volumes in these patients [68].

Kidney disease is also responsible for brain structural changes. Hemodialysis patients have more extent white matter disease and cerebral atrophy compared with controls without known kidney disease. Hemodialysis patients also have a high prevalence of unrecognized infarcts [69]. Smoke [70] and alcohol abuse [71], hyperlipidemia [50,72], depression [73], traumatic brain injury $[74,75]$ and many other morbid conditions have also been correlated to increased risk for $\mathrm{AD}$ and brain structural changes.

In our study, all the above morbid conditions co- calculated, however, there are few differences between similar studies that might influence the outcome. All of them have significantly younger participants and smaller samples. Some of them also compare specific ROIs which may not be included in our analysis, but we believe that we could assess their impact on the total brain volume. Finally, all the above studies compare patients to healthy participants whereas in our case analysis performed only to $\mathrm{AD}$ patients. It is also noteworthy that significant systematic illnesses were excluded in the very beginning.

Age correlates with a reduction in human brain volume even in older adults who are unlikely to be in a presymptomatic stage of AD [76]. In our study age seems to have a statistically important correlation with left and right cerebral white matter, and consequently with the total normalized brain volume as well. This age-effect on brain volumes is consistent with previous reports in the literature [77]. The volume decrease in entorhinal cortex and hippocampus areas is strongly associated with $\mathrm{AD}[78,79]$. In our case, the entorhinal cortex volume seems to reduce as co morbidity increases, even though the correlation is marginally not significant. Further study is needed with a larger sample size to support the above notion strongly.

The available evidence suggests that hippocampal atrophy is the starting point of the pathogenesis of $\mathrm{AD}$ and a significant number of patients with hippocampal atrophy will develop AD. Some of the factors associated with the development of hippocampal atrophy in $\mathrm{AD}$ have been identified, i.e., hypertension, DM, hyperlipidemia, seizures, affective disturbances, and stress. Hypertension can potentially damage the hippocampus through ischemia caused by atherosclerosis and cerebral amyloid angiopathy. DM can produce hippocampal lesions via both vascular and non-vascular pathologies and can reduce the threshold for hippocampal damage. Affective disturbances and stress are proposed to increase corticosteroidinduced hippocampal damage in many different ways [80].

Finally, gender is a significant co-factor in hippocampal volume studies. There is evidence of smaller hippocampal volumes in males, even though the atrophy progression is faster in females [81,82]. Our results support the above notion, finding gender correlation with the right and the left hippocampal volume. Hippocampal volumes are smaller in male than in female (Figure 1), which is consistent with the existing literature.

The initial assumption of this study was that co morbidity quantified by CIRS index would affect MRI brain volumes. Our results did not show an accumulative impact of co morbid conditions on the brain atrophy in specific brain areas of interest, although the normalized brain volume is, marginally, not significantly correlated with CIRS index. These results might be explained by the fact that the comorbidity burden is usually related to aging, and aging alone correlates with brain shrinkage. Moreover, neurodegenerative disease, in our sample, was already established when the measurements were made. So, we could assume that the atrophy caused by the disease was greater, compared to the atrophy caused by any other morbid condition in these specific areas.

Our study is a cross-sectional study of a population already diagnosed with AD. According to our research in the literature, there is no other study which correlates these co morbidity indexes of the patients with AD with MRI findings. Many studies nowadays, focus on the comorbidity in AD, but there is a variety of results since different co morbidity indexes have been used (Geriatric Index of Comorbidity [83] or Comorbidity Index and Score of Charlson [84]).

\section{Conclusion}

Co morbidities, although, according to the literature, worsen cognitive and/or behavioral symptoms in AD patients, make them more frail and more susceptible to pharmacological AEs than the older population without dementia [10], based on our results, they do not largely influence the brain structures volume additionally to the neurodegenerative disease. 


\section{Disclosure Statement}

The authors report no actual or potential conflict of interest. This paper is not under consideration by any other journal, and it has not previously published. The corresponding author takes full responsibility for the data, the analyses and interpretation and the conduct of the research, as well as access to all the data. All authors have seen and agreed with the contents of the manuscript.

\section{Acknowledgment}

The data for this study were collected for InnoMed (Innovative Medicines in Europe), an Integrated Project funded by the European Union of the Sixth Framework program priority FP6-2004LIFESCIHEALTH-5, Life Sciences, Genomics and Biotechnology for Health, Health Research Council of Academy of Finland and strategic funding for UEFBRAIN (HS), The Gamla Tjänarinnor Foundation (WE), The Swedish Alzheimer's Association (WE) and Swedish Brain Power (WE).

\section{References}

1. Alzheimer's Disease International (2015) World alzheimer report 2015: the global impact of dementia. Alzheimer's Dis International World Alzheimer Rep.

2. Bertram L, Lill CM, Tanzi RE (2010) The genetics of Alzheimer disease: back to the future. Neuron 68(2): 270-281.

3. Andersen K, Launer LJ, Dewey ME, Letenneur L, Ott A, et al. (1999) Gender differences in the incidence of $\mathrm{AD}$ and vascular dementia: The EURODEM Studies. EURODEM Incidence Research Group. Neurology 53: 1992-1997.

4. Fratiglioni L, Viitanen M, von Strauss E, Tontodonati V, Herlitz A, et al. (1997) Very old women at highest risk of dementia and Alzheimer's disease: incidence data from the Kungsholmen Project, Stockholm. Neurology 48(1): 132-138.

5. Lapane KL, Gambassi G, Landi F, Sgadari A, Mor V, et al. (2001) Gender differences in predictors of mortality in nursing home residents with AD. Neurology 56(5): 650-654.

6. Gambassi G, Lapane KL, Landi F, Sgadari A, Mor V, et al. (1999) Gender differences in the relation between comorbidity and mortality of patients with Alzheimer's disease. Systematic assessment of geriatric drug use via epidemiology (SAGE) study group. Neurology 53(3): 508-516.

7. Hall SF (2006) A user's guide to selecting a comorbidity index for clinical research. J Clin Epidemiol 59(8): 849-55.

8. Formiga F, Ferrer A, Sanz H, Marengoni A, Alburquerque J, et al. (2013) Patterns of comorbidity and multimorbidity in the oldest old: the Octabaix study. Eur J Intern Med 24(1): 40-44.

9. Lin PJ, Fillit HM, Cohen JT, Neumann PJ (2013) Potentially avoidable hospitalizations among Medicare beneficiaries with Alzheimer's disease and related disorders. Alzheimers Dement 9(1): 30-38.

10. Clodomiro A, Gareri P, Puccio G, Frangipane F, Lacava R, et al. (2013) Somatic comorbidities and Alzheimer's disease treatment. Neurol Sci 34(9): 1581-1589.

11. Shen HN, Lu CL, Li CY (2012) Dementia increases the risks of acute organ dysfunction, severe sepsis and mortality in hospitalized older patients: a national population-based study. PLoS One 7(8): e42751.

12. Martín-García S, Rodríguez-Blázquez C, Martínez-López I, MartínezMartín P, Forjaz MJ (2013) Comorbidity, health status, and quality of life in institutionalized older people with and without dementia. Int Psychogeriatr 25(7): 1-8.
13. Iijima K, Iimuro S, Shinozaki T, Ohashi Y, Sakurai T, et al. (2012) Lower physical activity is a strong predictor of cardiovascular events in elderly patients with type 2 diabetes mellitus beyond traditional risk factors: the Japanese Elderly Diabetes Intervention Trial. Geriatr Gerontol Int 12(1): 77-87.

14. Umegaki H (2012) Neurocognitive dysfunction in old diabetes: management and treatment. Adv Exp Med Biol 771: 465-470.

15. Exalto LG, Whitmer RA, Kappele LJ, Biessels GJ (2012) An update on type 2 diabetes, vascular dementia and Alzheimer's disease. Exp Gerontol 47(11): 858-864.

16. Bellew KM, Pigeon JG, Stang PE, Fleischman W, Gardner RM, et al. (2004) Hypertension and the rate of cognitive decline in patients with dementia of the Alzheimer type. Alzheimer Dis Assoc Disord 18(4): 208-213.

17. Skoog I, Gustafson D (2006) Update on hypertension and Alzheimer's disease. Neurol Res 28(6): 605-611.

18. Korczyn AD (2005) The under diagnosis of the vascular contribution to dementia. J Neurol Sci 229-230: 3-6.

19. Luchsinger JA, Mayeux R (2004) Cardiovascular risk factors and Alzheimer's disease. Curr Atheroscler Rep 6(4): 261-266.

20. Schubert CC, Boustani M, Callahan CM, Perkins AJ, Carney CP, et al. (2006) Comorbidity profile of dementia patients in primary care: are they sicker? J Am Geriatr Soc 54(1): 104-109.

21. Lyketsos CG, Toone L, Tschanz J, Rabins PV, Steinberg M, et al. (2005) Population-based study of medical comorbidity in early dementia and "cognitive impairment, no dementia (CIND)": association with functional and cognitive impairment: The Cache County Study. Am J Geriatr Psychiatry 13(8): 656-664.

22. Slaughter SE, Hayduk LA (2012) Contributions of environment, comorbidity, and stage of dementia to the onset of walking and eating disability in long-term care residents. J Am Geriatr Soc 60(9): 16241631.

23. Durazzo TC, Insel PS, Weiner MW (2012) Greater regional brain atrophy rate in healthy elderly subjects with a history of cigarette smoking. Alzheimers Dement 8(6): 513-519.

24. Sutherland GT, Sheahan PJ, Matthews J, Dennis CVP, Sheedy DS, et al. (2013) The effects of chronic alcoholism on cell proliferation in the human brain. Exp Neurol 247: 9-18.

25. den Heijer T, Launer LJ, Prins ND, van Dijk EJ, Vermeer SE, et al. (2005) Association between blood pressure, white matter lesions, and atrophy of the medial temporal lobe. Neurology 64(2): 263-267.

26. Firbank MJ, Wiseman RM, Burton EJ, Saxby BK, O’Brien JT, et al. (2007) Brain atrophy and white matter hyperintensity change in older adults and relationship blood pressure. Brain atrophy, WMH change and blood pressure. J Neurol 254(6): 713-721.

27. Vogels SCM, Emmelot-Vonk MH, Verhaar HJJ, Koek HDL (2012) The association of chronic kidney disease with brain lesions on MRI or CT: a systematic review. Maturitas 71(4): 331-336.

28. Niida A, Niida R, Matsuda H, Inada T, Motomura M, et al. (2012) Identification atrophy of the subgenual anterior cingulate cortex particular subcallosal area, effective auxiliary means of diagnosis for major depressive disorder. Int J Gen Med 5: 667-674.

29. Lovestone S, Francis P, Strandgaard K (2007) Biomarkers for disease modification trials--the innovative medicines initiative and AddNeuroMed. J Nutr Health Aging 11(4): 359-361.

30. McKhann G, Drachman D, Folstein M, Katzman R, Price D, et al. (1984) Clinical diagnosis of Alzheimer's disease: report of the NINCDS-ADRDA Work Group under the auspices of Department of Health and Human Services Task Force on Alzheimer's Disease. Neurology 34(7): 939-944. 
31. American Psychiatric Association (1994) Diagnostic and statistical manual of mental disorders. Washington, USA.

32. Linn BS, Linn MW, Gurel L (1968) Cumulative illness rating scale. J Am Geriatr Soc 16(5): 622-626.

33. Miller MD, Paradis CF, Houck PR, Mazumdar S, Stack JA, et al. (1992) Rating chronic medical illness burden in geropsychiatric practice and research: application of the Cumulative Illness Rating Scale. Psychiatry Res 41(3): 237-248.

34. Salvi F, Miller MD, Grilli A, Giorgi R, Towers AL, et al. (2008) A manual of guidelines to score the modified cumulative illness rating scale and its validation in acute hospitalized elderly patients. J Am Geriatr Soc 56(10): 1926-1931.

35. Jack CR, Bernstein MA, Fox NC, Thompson P, Alexander G, et al. (2008) The Alzheimer's disease neuroimaging initiative (ADNI): MRI methods. ] Magn Reson Imaging 27(4): 685-691.

36. Sled JG, Zijdenbos AP, Evans AC (1998) A nonparametric method for automatic correction of intensity nonuniformity in MRI data. IEEE Trans Med Imaging 17(1): 87-97.

37. Zijdenbos AP, Forghani R, Evans AC (2002) Automatic "pipeline" analysis of 3-D MRI data for clinical trials: application to multiple sclerosis. IEEE Trans Med Imaging 21(10): 1280-1291.

38. Collins D, Holmes C (1995) Automatic 3-D model-based neuroanatomical segmentation. Brain Mapp 3(3): 190-208.

39. Fischl B, Salat DH, Busa E, Albert M, Dieterich M, et al. (2002) Whole Brain Segmentation. Neuron 33(3): 341-355.

40. Fischl B, Salat DH, van der Kouwe AJW, Makris N, Ségonne F, et al. (2004) Sequence-independent segmentation of magnetic resonance images. Neuroimage 23(1): S69-S84.

41. Desikan RS, Ségonne F, Fischl B, Quinn BT, Dickerson BC, et al. (2006) An automated labeling system for subdividing the human cerebral cortex on MRI scans into gyral based regions of interest. Neuroimage 31(3): 968-980.

42. Pantel J, O Leary DS, Cretsinger K, Bockholt HJ, Keefe H, et al. (2000) A new method for the in vivo volumetric measurement of the human hippocampus with high neuroanatomical accuracy. Hippocampus 10(6): 752-758.

43. Mangialasche F, Westman E, Kivipelto M, Muehlboeck JS, Cecchetti R, et al (2013) Classification and prediction of clinical diagnosis of Alzheimer's disease based on MRI and plasma measures of $\alpha-/ \gamma$-tocotrienols and $\gamma$-tocopherol. J Intern Med 273(6): 602-621.

44. Bäckman L, Jones S, Small BJ, Agüero Torres H, Fratiglioni L (2003) Rate of cognitive decline in preclinical Alzheimer's disease: the role of comorbidity. J Gerontol B Psychol Sci Soc Sci 58(4): 228-236.

45. Fu C, Chute DJ, Farag ES, Garakian J, Cummings JL, et al. (2004) Comorbidity in dementia: an autopsy study. Arch Pathol Lab Med 128(1): 32-38.

46. Morrow LA, Snitz BE, Rodriquez EG, Huber KA, Saxton JA (2009) High medical co-morbidity and family history of dementia is associated with lower cognitive function in older patients. Fam Pract 26(5): 339-343.

47.Zekry D, Herrmann FR, Grandjean R, Meynet MP, Michel JP, et al. (2008) Demented versus non-demented very old inpatients: the same comorbidities but poorer functional and nutritional status. Age Ageing 37(1): 83-89.

48. Aubert L, Pichierri S, Hommet C, Camus V, Berrut G, et al. (2015) Association between comorbidity burden and rapid cognitive decline in individuals with mild to moderate Alzheimer's disease. J Am Geriatr Soc 63(3): 543-547.

49. Formiga F, Fort I, Robles MJ, Riu S, Sabartes O, et al. (2009) Comorbidity and clinical features in elderly patients with dementia: differences according to dementia severity. J Nutr Health Aging 13(5): 423-427.
50. Beeri MS, Ravona-Springer R, Silverman JM, Haroutunian V (2009) The effects of cardiovascular risk factors on cognitive compromise. Dialogues Clin Neurosci 11(2): 201-212.

51. Duron E, Rigaud AS, Dubail D, Mehrabian S, Latour F, et al. (2009) Effects of antihypertensive therapy on cognitive decline in Alzheimer's disease. Am J Hypertens 22(9): 1020-1024.

52. Fernández Martínez M, Castro Flores J, Pérez de Las Heras S, Mandaluniz Lekumberri A, Gordejuela Menocal M, et al. (2008) Risk factors for dementia in the epidemiological study of Munguialde County (Basque Country-Spain). BMC Neurol 8: 39.

53. Dai W, Lopez O, Carmichael O, Becker J, Kuller LH, et al. (2008) Abnormal regional cerebral blood flow in cognitively normal elderly subjects with hypertension. Stroke 39(2): 349-354.

54. Duron E, Hanon 0 (2008) Hypertension, cognitive decline and dementia. Arch Cardiovasc Dis 101(3): 181-189.

55. Abellan van Kan G, Rolland Y, Nourhashémi F, Coley N, Andrieu S, et al. (2009) Cardiovascular disease risk factors and progression of Alzheimer's disease. Dement Geriatr Cogn Disord 27(3): 240-246.

56. Van Dijk EJ, Prins ND, Vrooman HA, Hofman A, Koudstaal PJ, et al. (2008) Progression of cerebral small vessel disease in relation to risk factors and cognitive consequences: Rotterdam Scan study. Stroke 39(10): 2712-2719.

57. Gao S, Jin Y, Unverzagt FW, Liang C, Hall KS, et al. (2009) Hypertension and cognitive decline in rural elderly Chinese. J Am Geriatr Soc 57(6): 1051-1057.

58. Kearney Schwartz A, Rossignol P, Bracard S, Felblinger J, Fay R, et al. (2009) Vascular structure and function is correlated to cognitive performance and white matter hyperintensities in older hypertensive patients with subjective memory complaints. Stroke 40(4): 1229-1236.

59. Chen X, Wen W, Anstey KJ, Sachdev PS (2009) Prevalence, incidence, and risk factors of lacunar infarcts in a community sample. Neurology 73(4): 266-272.

60. Godin 0, Maillard P, Crivello F, Alpérovitch A, Mazoyer B, et al. (2009) Association of white-matter lesions with brain atrophy markers: the three-city Dijon MRI study. Cerebrovasc Dis 28(2): 177-184.

61. Veglio F, Paglieri C, Rabbia F, Bisbocci D, Bergui M, et al. (2009) Hypertension and cerebrovascular damage. Atherosclerosis 205(2): 331-341.

62. Erbay S, Han R, Aftab M, Zou KH, Polak JF, et al. (2008) Is intracranial atherosclerosis an independent risk factor for cerebral atrophy? A retrospective evaluation. BMC Neurol 8: 51

63. Beauchet O, Celle S, Roche F, Bartha R, Montero Odasso M, et al. (2013) Blood pressure levels and brain volume reduction: a systematic review and meta-analysis. J Hypertens 31(10): 1502-1516.

64. Meurs M, Groenewold NA, Roest AM, van der Wee NJA, Veltman DJ, et al. (2015) The associations of depression and hypertension with brain volumes: Independent or interactive? NeuroImage Clin 8: 79-86.

65. Lee JH, Yoon S, Renshaw PF, Kim TS, Jung JJ, et al. (2013) Morphometric changes in lateral ventricles of patients with recent-onset type 2 diabetes mellitus. PLoS One 8: e60515.

66. Vogels RLC, van der Flier WM, van Harten B, Gouw AA, Scheltens P, et al. (2007) Brain magnetic resonance imaging abnormalities in patients with heart failure. Eur J Heart Fail 9(10): 1003-1009.

67. Kumar R, Yadav SK, Palomares JA, Park B, Joshi SH, et al. (2015) Reduced regional brain cortical thickness in patients with heart failure. PLoS One 10: e0126595.

68. Alosco ML, Brickman AM, Spitznagel MB, Griffith EY, Narkhede A, et al. (2013) The adverse impact of type 2 diabetes on brain volume in heart failure. J Clin Exp Neuropsychol 35(3): 309-318. 
69. Drew DA, Bhadelia R, Tighiouart H, Novak V, Scott TM, et al. (2013) Anatomic brain disease in hemodialysis patients: a cross-sectional study. Am J Kidney Dis 61(2): 271-278.

70. Duriez Q, Crivello F, Mazoyer B (2014) Sex-related and tissue-specific effects of tobacco smoking on brain atrophy: assessment in a large longitudinal cohort of healthy elderly. Front Aging Neurosci 6: 299.

71. Beck A, Wüstenberg T, Genauck A, Wrase J, Schlagenhauf F, et al. (2012) Effect of brain structure, brain function, and brain connectivity on relapse in alcohol-dependent patients. Arch Gen Psychiatry 69(8): 842852.

72. Debette S, Seshadri S, Beiser A, Au R, Himali JJ, et al. (2011) Midlife vascular risk factor exposure accelerates structural brain aging and cognitive decline. Neurology 77(5): 461-468.

73. Mackin RS, Tosun D, Mueller SG, Lee JY, Insel P, et al. (2013) Patterns of reduced cortical thickness in late-life depression and relationship to psychotherapeutic response. Am J Geriatr Psychiatry 21(8): 794-802.

74. Lee YK, Hou SW, Lee CC, Hsu CY, Huang YS, et al. (2013) Increased risk of dementia in patients with mild traumatic brain injury: a nationwide cohort study. PLoS One 8: e62422.

75. Zhou Y, Kierans A, Kenul D, Ge Y, Rath J, Reaume J, et al. (2013) Mild traumatic brain injury: longitudinal regional brain volume changes. Radiology 267(3): 880-890.

76. Fjell AM, McEvoy L, Holland D, Dale AM, Walhovd KB, et al. (2013) Brain changes in older adults at very low risk for Alzheimer's disease. J Neurosci 33(19): 8237-8242.

77. Pantoni L (2010) Cerebral small vessel disease: from pathogenesis and clinical characteristics to therapeutic challenges. Lancet Neurol 9(7): 689-701.
78. Khan W, Westman E, Jones N, Wahlund LO, Mecocci P, et al. (2015) Automated hippocampal subfield measures as predictors of conversion from mild cognitive impairment to alzheimer's disease in two independent cohorts. Brain Topogr 28(5): 746-759.

79. Aguilar C, Muehlboeck JS, Mecocci P, Vellas B, Tsolaki M, et al. (2014) Application of a MRI based index to longitudinal atrophy change in Alzheimer disease, mild cognitive impairment and healthy older individuals in the add neuro med cohort. Front Aging Neurosci 6: 145.

80. Dhikav V, Anand K (2011) Potential predictors of hippocampal atrophy in Alzheimer's disease. Drugs Aging 28(1): 1-11.

81. Zhang Y, Qiu C, Lindberg O, Bronge L, Aspelin P, et al. (2010) Acceleration of hippocampal atrophy in a non-demented elderly population: the SNAC-K study. Int Psychogeriatrics 22(1): 14-25.

82. Velickaite V, Ferreira D, Cavallin L, Lind L, Ahlström H, et al. (2017) Medial temporal lobe atrophy ratings in a large 75-year-old populationbased cohort: gender-corrected and education-corrected normative data. Eur Radiol 28(4): 1739-1747.

83. Rozzini R, Frisoni GB, Ferrucci L, Barbisoni P, Sabatini T, et al. (2002) Geriatric Index of Comorbidity: validation and comparison with other measures of comorbidity. Age Ageing 31(4): 277-285.

84. McGregor JC, Kim PW, Perencevich EN, Bradham DD, Furuno JP, et al. (2005) Utility of the chronic disease score and charlson comorbidity index as comorbidity measures for use in epidemiologic studies of antibiotic-resistant organisms. Am J Epidemiol 161(5): 483-493.
Creative Commons Attribution 4.0 International License

For possible submissions Click Here

\section{Submit Article}

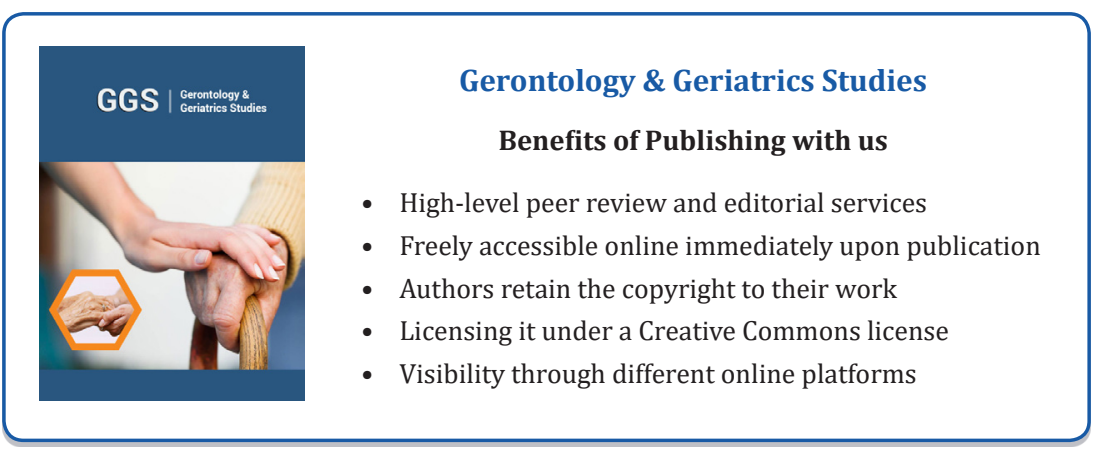

